\title{
Antifungal Susceptibility Pattern of Clinical Isolates of Candida from a Tertiary Care Hospital in Chhattisgarh, India
}

Dr. Neeta Gade ${ }^{*}$, Dr. Arvind Neral ${ }^{2}$, Dr. Niza Monga ${ }^{3}$, Dr. Parag Aradhey ${ }^{4}$, Dr. Rachna Singh ${ }^{3}$, Dr. Rekha Barapatre ${ }^{3}$, Dr. Nikita Sherwani ${ }^{5}$, Dr. S.G. Joshi ${ }^{6}$

\author{
${ }^{1}$ Assistant Professor, Microbiology, All India Institute of Medical Sciences, Nagpur, India \\ ${ }^{2}$ Professor,Microbiology, Pt Jawaharlal Nehru Memorial Medical College, Raipur, India \\ ${ }^{3}$ Assistant Professor,Microbiology, Pt Jawaharlal Nehru Memorial Medical College, Raipur, India \\ ${ }^{4}$ Senior Resident, Medicine, Jawaharlal Nehru Medical college, Sawangi, India, 5Associate Professor, Microbiology, Pt Jawaharlal Nehru Memorial \\ Medical College, Raipur, India \\ ${ }^{6}$ Professor, Microbiology, Grant Medical College, Sir J.J.group of hospitals, Mumbai, India
}

DOI: $\underline{10.36348 / \text { sjpm.2019.v04i12.007 }}$

| Received: 20.12.2019| Accepted: 27.12.2019 | Published: 30.12.2019

*Corresponding author: Dr. Neeta Gade

\section{Abstract}

Candida continues to be leading cause of morbidity and mortality in large population of immunocompromised and hospitalized patients. Invasive Candidiasis due to non-albicans candida has been on the rise in last few years. Incidence rates vary geographically, often because of different patient populations studied. The present study was conducted to find out the species distribution and antifungal susceptibility of Candida species from different sources and patient population of our tertiary care hospital. A total of 103 Candida species were isolated from the different clinical specimens of suspected candida infection cases, In this study, it was observed that candidiasis can occur at all ages and in both sexes. $82(79.6 \%)$ isolates were obtained from cases admitted in different inpatient departments of which 51 (49.5\%) accounted for isolates from various ICUs mainly NICU. Most of the isolates obtained were from urine samples (44.6\%) followed by blood (34.9\%). Non albicans Candida were isolated at a higher rate (52.8\%) than Candida albicans (47.5\%). Among all species of Candida commonest isolate was C. albicans (47.5\%) followed by C. tropicalis (26.21\%). Overall high suceptibility to voriconazole and Amphotericin B (99.03\%). This study emphasizes the need for monitoring local epidemiologic data and antifungal susceptibility pattern of candida isolates for proper treatment.

Keywords: Candida, Antifungals susceptibility, non-albicans Candida.

Copyright @ 2019: This is an open-access article distributed under the terms of the Creative Commons Attribution license which permits unrestricted use, distribution, and reproduction in any medium for non-commercial use (NonCommercial, or CC-BY-NC) provided the original author and sources are credited.

\section{INTRODUCTION}

Developments in diagnostic modalities and therapeutic options has contributed to invasive fungal infections and colonisation in large population of immunocompromised patients and /or those hospitalized with serious underlying conditions. Among these risk groups, Candida spp. is a leading cause of morbidity and mortality. There has been increase in the rate of candida infections in different clinical settings throughout the world [1]. Candidiasis which accounts for $66-80 \%$ of fungal infections, is a primary or secondary infection involving a member of genus Candida. Candida species are associated with vast clinical spectrum of human infections ranging from superficial infection of the skin, mucus membranes to life threatening candidemia, and hospital-acquired infections.[2] Invasive candidiasis includes severe diseases such as candidemia, disseminated infections,
CNS infections, endophthalmitis, osteomyelitis. Candidemia which is a bloodstream infection by Candida species is the most common and fatal clinical manifestation of invasive candidiasis, and contribute to large number of morbidity and mortality in hospitalized patients [3]. Candidemia is the most common nosocomial bloodstream infection reported from USA and Europe [4] Similarly, Candida spp contribute to 10$15 \%$ of nosocomial urinary tract infections (UTIs).

Most common precipitating factors of invasive candidiasis are HIV/AIDS, underlying malignancies, invasive interventions, use of broad-spectrum antibiotics, parenteral alimentation, and use of intravascular catheters, long-term hospitalization, and immunosuppressive agents.

Though the Candida spp. forms the normal flora of human oral, gastrointestinal and genitourinary 
tracts, it causes clinical infection when the host becomes debilitated or immunocompromised. The genus Candida includes more than 150 heterogeneous group species out of which approximately 20 different Candida species are pathogenic to human.

Although Candida albicans remains major cause of candidiasis in spite of its dwindling share. The epidemiology of non-albicans candida has been on the rise in last few years.[2] Five species of Candida namely, C. albicans, C. glabrata, C. parapsilosis, C. tropicalis and $\mathrm{C}$. krusei are reported to cause more than $90 \%$ of invasive infections, although the relative distribution of the species depends on the geographical area, patient population and predisposing conditions, local hospital related factors, and the types of antifungal agents received[5].

The extensive use of antifungals for prophylaxis became the leading cause of colonization of non-albicans Candida (NAC) species and increasing resistance to antifungal drugs [6].

Changing etiology of candidiasis and emerging antifungal resistance necessitates early identification, speciation and antifungal susceptibility testing to select the appropriate antifungal agent to prevent the treatment failure and also to study the local epidemiology of antifungal resistance.

There are very limited data available on distibution and the antifungal susceptibility of Candida spp. in this region. Herein we studied distribution of Candida spp. isolated from various clinical specimens at our tertiary hospital, their susceptibility to antifungal agents and associated risk factors. Lack of data in this region so far needs to be addresed.

\section{MATERIAL \& METHODS}

We evaluated samples from patients of various age groups being treated for suspected Candidiasis at different departments of our tertiary care hospital in Central India over the period of four months. Detailed clinical and treatment history of patients was recorded. Yeast cultures obtained from blood, urine, sputum, bronchoalveolar lavage, cerebrospinal fluid, pus, peritoneal fluid, high vaginal/ cervical swab were included in the study. The isolation and identification of fungi were performed using standard methods in the microbiology laboratory. Samples were subjected to Gram's stain to look for presence of Gram positive yeast like budding cells with pseudohyphae and $\mathrm{KOH}$ mount. The samples were inoculated on Sabouraud's dextrose agar (SDA) with choramphenicol \& Blood agar and incubated at $37^{\circ} \mathrm{C}$ and $25^{\circ} \mathrm{C}$ [7].

\section{Identification \& Speciation}

Suspected colonies of Candida on SDA were confirmed by Gram's stain. Further species identification was done by a) germ tube test b) Dalmau plate culture for Chlamydospore production c) inoculation on chromogenic medium d) carbohydrate utilization patterns by Sugar Assimilation Tests. Germ tube test was carried out by inoculating isolated yeast cells into $0.5 \mathrm{ml}$ of pooled human serum in a small tube and incubaion at $37{ }^{\circ} \mathrm{C}$ for 2 hours. Germ tubes formation was observed microscopically as tubular elongation extending from the yeast cells without constriction or septa at the point of attachment to the yeast cells. Dalmu plate cultures were done by inoculation on corn meal agar containing $1 \%$ Tween 80 . Plates were incubated at $30^{\circ} \mathrm{C}$ for $2-5$ days and studied microscopically for the presence of pseudohyphae, chlamydospores \& blastospores. Isolated candida species were subcultured onto chromogenic Candida medium (HICHROME Candida agar) and incubated at $37^{\circ} \mathrm{C}$ for $48 \mathrm{hr}$. Presumptive species identification was done based on specific colony colors produced by the chromogenic substrates in the medium [Image 1 ]. All isolates were identified by carbohydrate assimilation tests using the Vitek2 Compact (Biomerieux, France) using Vitek2 cards for identification of yeast and yeast like organisms (ID-YST cards) kits.

Few isolates were sent to Mycology Reference Laboratory, PGIMER, and Chandigarh for confirmation by MALDI-TOFF.

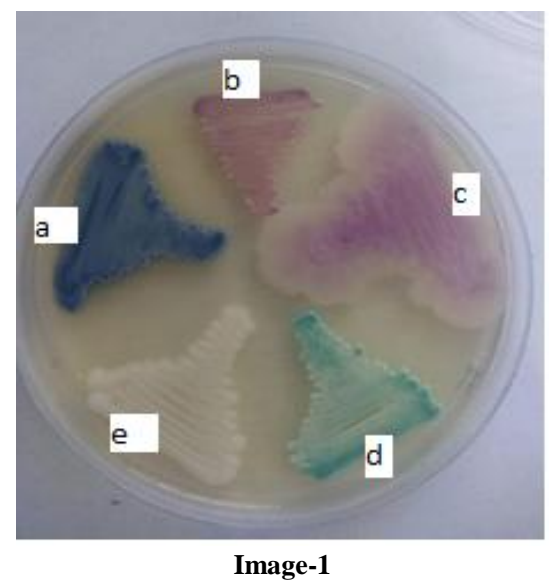

Candida chrome agar showing growth: a) C. tropicalis, b) C. utilis c) C. krusei d). albicans e) C. lusitanae

\section{Antifungal Susceptibility Test}

Antifungal susceptibility testing was performed for all the isolates of Candida using disc diffusion method on Mueller Hinton agar supplemented with $2 \%$ glucose and $0.5 \mu \mathrm{g} / \mathrm{ml}$ of methylene blue as per the procedure described in the Clinical and Laboratory Standard Institute (CLSI, 2009) against two antifungal agents. Cell suspensions of individual Candida strains were prepared in $5 \mathrm{ml}$ saline solution. The turbidity was adjusted to yield 0.5 McFarland standards. The commercially available antifungal discs of Fluconazole $(25 \mu \mathrm{g})$, Voriconazole $(1 \mu \mathrm{g})$ were used and zones of inhibition were measured after 20- 24 hours of incubation at $37^{\circ} \mathrm{C}$ [8]. [Image 2]. 
Zone diameter interpretative standards for tested antifungal agents against Candida species were:

\begin{tabular}{|c|c|c|c|}
\hline \multirow{2}{*}{ Antifungal agent } & \multicolumn{3}{|c|}{ Zone diameter $(\mathbf{m m})$} \\
\cline { 2 - 4 } & Sensitive & Intermediate & Resistant \\
\hline Fluconazole $(10 \mu \mathrm{g}$ & $\geq 19$ & $15-18$ & $\leq 14$ \\
\hline Voriconazole $(1 \mu \mathrm{g})$ & $\geq 17$ & $14-16$ & $\leq 13$ \\
\hline
\end{tabular}

Anti-fungal susceptibility was also performed with AST YS01 Kits on Vitek 2 compact system. Standard operative procedures as described by the manufacturer were followed. The Antifungal susceptibility values to amphotericin B, fluconazole, voriconazole and caspofungin were interpreted according to the new species-specific clinical breakpoints defined by the CLSI in 2012 [new CLSI breakpoints] [9]. Species-specific breakpoints for antifungal agents for the most common species of Candida isolates.

\begin{tabular}{|c|c|c|c|c|c|}
\hline \multirow[t]{2}{*}{ Antifungal agent } & \multirow[t]{2}{*}{ Species } & \multicolumn{4}{|c|}{ Breakpoints $(\mu \mathrm{g} / \mathrm{ml})$} \\
\hline & & $\mathbf{S}$ & I & $\mathbf{R}$ & S-DD \\
\hline \multirow[t]{6}{*}{ Amphotericin B } & C.albicans & $<1$ & - & $\geq 1$ & - \\
\hline & C.parapsilosis & $<1$ & - & $\geq 1$ & - \\
\hline & C.guilliermondii & $<1$ & - & $\geq 1$ & - \\
\hline & C.glabrata & $<1$ & - & $\geq 1$ & - \\
\hline & C.krusei & $<1$ & - & $\geq 1$ & - \\
\hline & C. tropicalis & $<1$ & - & $\geq 1$ & - \\
\hline \multirow[t]{6}{*}{ Fluconazole } & C.albicans & $\leq 2$ & - & $\geq 8$ & 4 \\
\hline & C.parapsilosis & $\leq 2$ & - & $\geq 8$ & 4 \\
\hline & C.guilliermondii & - & - & - & - \\
\hline & C.glabrata & - & - & $\geq 64$ & $\leq 32$ \\
\hline & C.krusei & - & - & - & - \\
\hline & C. tropicalis & $\leq 2$ & - & $\geq 8$ & 4 \\
\hline \multirow[t]{6}{*}{ Voriconazole } & C.albicans & $\leq 0.12$ & $0.25-0.5$ & $\geq 1$ & - \\
\hline & C.parapsilosis & $\leq 0.12$ & $0.25-0.5$ & $\geq 1$ & - \\
\hline & C.guilliermondii & $\leq 2$ & 4 & $\geq 8$ & - \\
\hline & C.glabrata & - & - & $\geq 1$ & - \\
\hline & C.krusei & 0.5 & 1 & 2 & - \\
\hline & C. tropicalis & $\leq 0.12$ & $0.25-0.5$ & $\geq 1$ & - \\
\hline \multirow[t]{6}{*}{ Caspofungin } & C.albicans & $\leq 0.25$ & 0.5 & $\geq 1$ & - \\
\hline & C.parapsilosis & $\leq 2$ & 4 & $\geq 8$ & - \\
\hline & C.guilliermondii & $\leq 2$ & 4 & $\geq 8$ & - \\
\hline & C.glabrata & $\leq 0.12$ & 0.25 & $\geq 0.5$ & - \\
\hline & C.krusei & $\leq 0.25$ & 0.5 & $\geq 1$ & - \\
\hline & C. tropicalis & $\leq 0.25$ & 0.5 & $\geq 1$ & - \\
\hline
\end{tabular}

S-Susceptible R- Resistant I- Intermediate S-DDSusceptible Dose Dependant

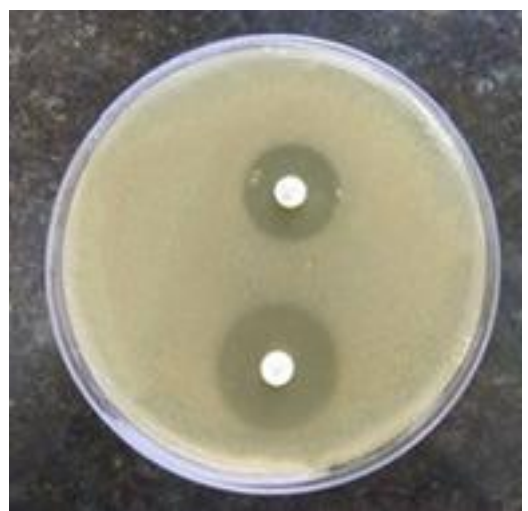

\section{Image-2}

Antifungal susceptibility testing of Candida isolates by disc diffusion method

\section{RESULTS}

A total of 103 Candida species were isolated from the different clinical specimens during the study period. Most of the isolates obtained were from urine specimens $(44.6 \%)$ followed by blood $(34.9 \%)$ and high vaginal swabs (10.6\%) [Table 1] [Fig 1] From females, $57(55.3 \%)$ candida were isolated and 46 isolates were from male patients $(44.6 \%)$. The highest number of isolates was from the age group of $0-1$ year followed by $21-40$ yrs. [Table 2]. 
In our study, among the candida species isolated, most common was Candida albicans (47.6\%) followed by Candida tropicalis $(26.2 \%)$ and Candida krusei $(8.7 \%)$. [Table 3] In the present study Non albicans Candida (NAC) were isolated at a higher rate (52.4\%) than Candida albicans (47.6\%) [Fig 2].

In this study, $82(79.6 \%)$ isolates were obtained from cases admitted in different inpatient departments of which $51(49.5 \%)$ accounted for isolates from various ICUs mainly NICU. Risk factors associated were found to be prolonged hospital stay, use of broad-spectrum antibacterial agents, chemotherapy for underlying malignancy, presence of intravascular catheters, diabetes mellitus, tuberculosis, pregnancy. We identified 32 neonates with candida blood stream infections. Predisposing factors observed in these neonates were extremely low birth weight, very low birth weight, prematurity, prolonged antibiotic therapy, indwelling catheterization.

In this study, antifungal susceptibility pattern by disk diffusion and microbroth dilution method by Vitek 2 system for fluconazole and voriconazole was found to be in agreement. Overall high suceptibility to voriconazole (100\%), Amphotericin B (96.1\%), Caspofungin (96.11), and fluconazole (89.3\%) was observed. All isolates of the species C. glabrata and C. krusei and $\mathrm{C}$. lusitanae were found to be susceptible to amphotericin B with MIC of $0.5 \mu \mathrm{g} / \mathrm{ml}$. Only one isolate of Candida albicans $(2.04 \%)$ isolated from blood was found to be resistant to Amphotericin B with MIC of $2 \mu \mathrm{g} / \mathrm{ml}$. MIC values for all the susceptible isolates ranged from 0.5 to $4 \mu \mathrm{g} / \mathrm{ml}$ for fluconazole, $<0.12$ to $0.25 \mu \mathrm{g} / \mathrm{ml}$ for Voriconazole, $<0.12$ to $0.25 \mu \mathrm{g} / \mathrm{ml}$ for Caspofungin, Amphotericin B $<0.25$ to $0.5 \mu \mathrm{g} / \mathrm{ml}$.

Table-1: Distribution of Candida isolates in various clinical samples

\begin{tabular}{|c|c|c|c|}
\hline Source & Number Of Candida Isolates & Male & Female \\
\hline Blood & $36(34.9 \%)$ & $24(23.3 \%)$ & $12(11.6 \%)$ \\
\hline Urine & $46(44.6 \%)$ & $17(16.5 \%)$ & $29(28.1 \%)$ \\
\hline Pus & $05(4.8 \%)$ & $02(1.9 \%)$ & $03(2.9 \%)$ \\
\hline Sputum & $03(2.9 \%)$ & $02(1.9 \%)$ & $01(1.9 \%)$ \\
\hline Peritoneal Fluid & $01(0.9 \%)$ & 0 & $01(1.9 \%)$ \\
\hline HVS & $11(10.6 \%)$ & 0 & $11(10.6 \%)$ \\
\hline CSF & $01(0.9 \%)$ & $01(1.9 \%)$ & 0 \\
\hline Total & 103 & $46(44.6 \%)$ & $57(55.3 \%)$ \\
\hline
\end{tabular}

Table-2: Demographic distribution of Candida species isolates

\begin{tabular}{|c|c|c|c|c|c|}
\hline \multirow{2}{*}{ Age group } & \multicolumn{2}{|c|}{$\begin{array}{c}\text { Candida albicans } \\
(\mathbf{n = 4 9})\end{array}$} & \multicolumn{2}{c|}{$\begin{array}{c}\text { Nonalbicans } \\
\text { Candida }(\mathbf{n = 5 4})\end{array}$} & \multirow{2}{*}{ Total } \\
\cline { 2 - 5 } & Male & Female & Male & Female & \\
\hline$<1$ & 03 & 01 & 22 & 08 & $34(33 \%)$ \\
\hline 1 - 10YR & 02 & 01 & 0 & 0 & $03(2.9 \%)$ \\
\hline $11-20$ YR & 01 & 05 & 0 & 05 & $11(10.7 \%)$ \\
\hline $21-30$ & 01 & 14 & 02 & 02 & $19(18.4 \%)$ \\
\hline $31-40$ & 02 & 04 & 03 & 04 & $13(12.6 \%)$ \\
\hline $41-50$ & 02 & 03 & 01 & 02 & $08(7.8 \%)$ \\
\hline $51-60$ & 02 & 01 & 0 & 03 & $06(5.8 \%)$ \\
\hline$>60$ & 03 & 02 & 02 & 02 & $09(8.7 \%)$ \\
\hline Total & 16 & 31 & 30 & 26 & $103(100 \%)$ \\
\hline
\end{tabular}

Table-3: Species distribution of Candida isolates

\begin{tabular}{|c|c|c|}
\hline Candida species & Total No of Isolates & Percentage \\
\hline Candida albicans & 49 & $47.6 \%$ \\
\hline Candida tropicalis & 27 & $26.2 \%$ \\
\hline Candida krusei & 09 & $8.7 \%$ \\
\hline Candida lusitanae & 08 & $7.8 \%$ \\
\hline Candida utilis & 08 & $7.8 \%$ \\
\hline
\end{tabular}




\begin{tabular}{|c|c|c|}
\hline Candida glabrata & 02 & $1.9 \%$ \\
\hline TOTAL & 103 & $100 \%$ \\
\hline
\end{tabular}

Table-4: Distribution pattern of Candida species in candidemia cases $(n=36)$

\begin{tabular}{|c|c|c|}
\hline Candida Species & Total No of Isolates & Percentage \\
\hline Candida albicans & 05 & $13.9 \%$ \\
\hline Candida krusei & 06 & $16.7 \%$ \\
\hline Candida lusitanae & 07 & $19.4 \%$ \\
\hline Candida tropicalis & 10 & $27.8 \%$ \\
\hline Candida utilis & 07 & $19.4 \%$ \\
\hline Candida glabrata & 01 & $2.7 \%$ \\
\hline
\end{tabular}

Table-5: Distribution pattern of Candida species in candiduria cases $(n=46)$

\begin{tabular}{|c|c|c|}
\hline Candida Species & $\begin{array}{c}\text { Total No of } \\
\text { Isolates }\end{array}$ & Percentage \\
\hline Candida albicans & 28 & $60.9 \%$ \\
\hline Candida krusei & 03 & $6.5 \%$ \\
\hline Candida tropicalis & 13 & $28.3 \%$ \\
\hline Candida utilis & 01 & $2.1 \%$ \\
\hline Candida glabrata & 01 & $2.1 \%$ \\
\hline
\end{tabular}

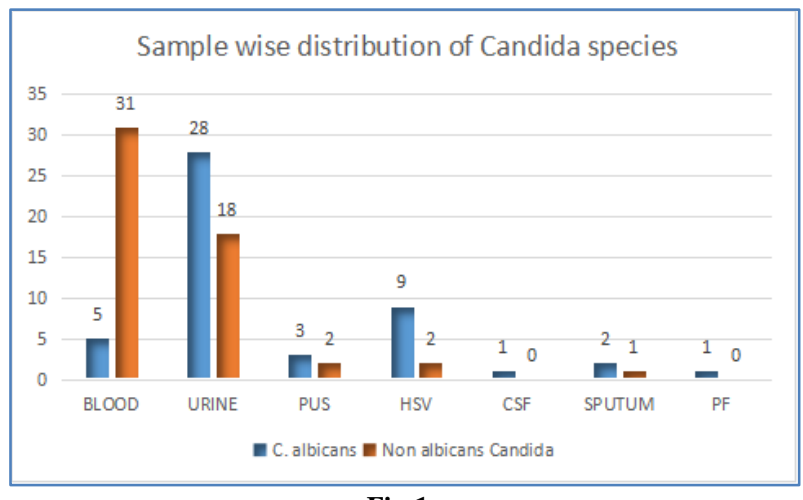

Fig-1

\section{Distribution of Candida isolates}

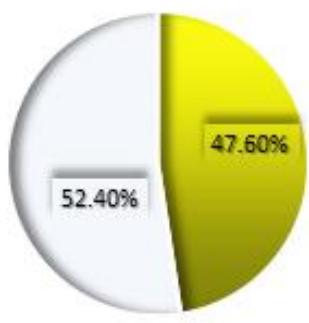

- Candida albicans = Nonalbicans Candida

Fungal infections, particularly those attributed to Candida species, are frequent complications for hospitalized patients contributing to increased morbidity and mortality and healthcare cost. Furthermore there is increasing prevalence of infections caused by nonalbicans Candida worldwide with various degree of sucseptibility to routinely use antifungal agents indicating the importance of laboratory diagnoses [10]. In this study, it was observed that candidiasis can occur at all ages and in both sexes. Majority of the patients were less than one year old and those admitted to NICU. The occurrence of Candida spp. infections in infants often involves the colonization of their mucous membranes or skin, which puts them at risk for invasive infections due to changes in their hostparasite equilibrium, prolonged hospital stay and use of broad spectrum antibiotics [11]. Our finding was similar to those reported by Almeida et al. [12]

In the present study, the distribution of Candida species in different clinical samples showed the highest number of isolates in urine $(44.6 \%)$, followed by blood(34.9\%), high vaginal swab (10.6\%). Our observation is similar with the studies of Furlaneto et al. [13] where most of the clinical isolates were from urine specimen $(86 \%)$ followed by blood $(19 \%)$ and Shanoo et al. [14] where most common clinical sample was urine $(38 \%)$ followed by sputum $(17 \%)$ and blood (10\%). Pfaller et al. [15] found that Candida species was seventh most common cause of nosocomial infection accounting for $25 \%$ of urinary tract infections in his studies.

\section{DISCUSSION}


In current study among 103 Candida isolates, the most common isolate was C. albicans (47.6\%), followed by C. tropicalis $(26.2 \%)$, C. krusei $(8.7 \%), \mathrm{C}$. lusitanae $(7.8 \%)$, C. utilis $(7.8 \%)$ and C. glabrata (1.9\%) respectively. Non albicans Candida were isolated at a higher rate $(52.4 \%)$ than Candida albicans $(47.6 \%)$ in our study which is in concordance with different studies from various parts of India suggesting non-C. albicans are emerging microbial trend in yeast infections [14-19].

The predominant NAC isolated in our tertiary care centre, was C. tropicalis. This agreed with the studies conducted by Basu et al. [20] and Yang et al. [21].

In the present study, C. tropicalis was the most frequent $(27.7 \%)$ species among the cases of candidemia. Several studies from India also reported C. tropicalis is the most frequent isolate in cases of candidemia among hospitalized patients [19]. There was significant difference in distribution of candida species in different parts of country [Table 6] In our study, second most commonly isolated species from blood were C. utilis (19.4\%) and C. lusitanae (19.4\%). These isolates were confirmed by MALDI-TOF mass spectrometry and were correctly idenfied by Vitek. C. utilis is anamorphic form of Pichia jandinii, known for its industrial applications as food additive and rarely associated with disease. There are only few case reports of C. utilis fungemia.[22] C. lusitaniae also an infrequent but emerging cause of nosocomial infections , accounts for only $1 \%$ of all candidemias [23]. In our study, these cases of candidemia were observed in neonates admitted to NICU. Underlying risk factors observed were extremely low birth weight, prematurity and use of broad- spectrum antimicrobial therapy. However, we could not find out the environmental source of these Candida species from surveillance cultures during the study period.

A high sensitivity of $\mathrm{C}$. albicans to antifungal agents was observed, corroborating other published works. [6,12] In present study, C. albicans isolates had a $97.9 \%$ susceptibility to Amphotericin B, a polyene antifungal which was comparable to finding by Capoor et al. [24]. In constrat to it, sagarika et al. [25] and Mokadas et al. [18] reported $100 \%$ susceptibility of C. albicans to Amphotericin B.

In this study there was no resistance recorded for voriconazole for all the candida species which is in agreement with the study by Samara et al. [26] whereas results from the latest ARTEMIS DISK Global Antifungal Surveillance Study of Candida species shows 5\% resistance for voriconazole [27].

In our study resistance of Candida against Fluconazole was more $(10.7 \%)$ in comparison to other antifungals used in this study. The study by Pfaller et al. [27] and Badiee et al. [2] had similar findings. Studies from different parts of India [29, 16, 25, 30, 6] reported higher resistance to fluconazole [Table 7]. Indiscrimate use of fluconazole and intrinsic resistance of few nonalbicans candida species contribute to fluconazole resistance. In our study all isolates of C. krusei were resistant to fluconazole.

Most Candida isolates were susceptible to caspofungin when considering new CLSI breakpoints, except for three isolates of $\mathrm{C}$. krusei and one isolate of C. tropicalis with an in vitro non-susceptibility rate of $33.3 \%$ and $3.7 \%$ respectively. European studies have also shown rare in vitro resistance to fluconazole, voriconazole and caspofungin among $\mathrm{C}$. albicans with increasing trend for fluconazole resistance among nonalbicans Candida isolates [26, 28].

Table-6: Frequency of Candida spp. isolation in different studies

\begin{tabular}{|l|l|l|l|l|}
\hline Author & Year & C. albicans & Nonalbicans Candida & C.tropicalis \\
\hline Basu et al. [20] & 2003 & $45.8 \%$ & 54.2 & $24.7 \%$ \\
\hline Yang et al. [21] & 2006 & $69 \%$ & $31 \%$ & $12.9 \%$ \\
\hline Mokadas et al. [18] & 2007 & $39.5 \%$ & $60.5 \%$ & 12.5 \\
\hline Adhikary et al. [19] & 2011 & $26.4 \%$ & $60.2 \%$ & $39.7 \%$ \\
\hline Shanoo et al. [14] & 2017 & $42 \%$ & $58 \%$ & $34 \%$ \\
\hline Sing et al. [6] & 2017 & $25.5 \%$ & $74.4 \%$ & $59 \%$ \\
\hline Present study & 2019 & $47.6 \%$ & $52.4 \%$ & $27.8 \%$ \\
\hline
\end{tabular}

Table-7: Comparative study of fluconazole and Amphotericin B resistance among Candida species

\begin{tabular}{|l|l|l|l|l|}
\hline Author & Year & Place & Fluconazole Resistance & Amphotericin B Resistance \\
\hline Roy et al. [29] & 2013 & Asam & $36.2 \%$ & $0 \%$ \\
\hline Jayalaxmi et al. [16] & 2014 & Hyderabad & $34.2 \%$ & $4.2 \%$ \\
\hline Sagarika et al. [25] & 2015 & Gujarat & $15.2 \%$ & $6.4 \%$ \\
\hline Halder et al. [30] & 2016 & West Bengal & $29 \%$ & $5.4 \%$ \\
\hline Singh et al. [6] & 2017 & Uttar Pradesh & $4.4 \%$ & $2.2 \%$ \\
\hline Present Study & 2018 & Chhattisgarh & $10.2 \%$ & $0.97 \%$ \\
\hline
\end{tabular}




\section{CONCLUSION}

The increasing incidence of candida infections and the emergence of antifungal resistance have emphasized the need for updated laboratory data to guide clinicians in selecting appropriate antifungal therapy.

\section{ACKNOWLEDGEMENT}

The authors acknowledge the help provided by Centre of advanced research in medical mycology, Post graduate Institute of Medical Education \& Research, Chandigarh.

\section{REFERENCES}

1. Bassetti, M., Peghin, M., \& Timsit, J. F. (2016). The current treatment landscape: candidiasis. Journal of Antimicrobial Chemotherapy, 71(suppl_2), ii13-ii22.

2. Badiee, P., Kordbacheh, P., Alborzi, A., Zeini, F., Mirhendy, H., \& Mahmoody, M. (2005). Fungal infections in solid organ recipients. Experimental and clinical transplantation: official journal of the Middle East Society for Organ Transplantation, 3(2), 385-389.

3. Zarin, M., \& Zarei, M. A. (2009). Invasive candidiasis; a review article.

4. Falagas, M. E., Roussos, N., \& Vardakas, K. Z. (2010). Relative frequency of albicans and the various non-albicans Candida spp among candidemia isolates from inpatients in various parts of the world: a systematic review. International Journal of Infectious Diseases, 14(11), e954-e966.

5. Spampinato, C., \& Leonardi, D. (2013). Candida infections, causes, targets, and resistance mechanisms: traditional and alternative antifungal agents. BioMed research international, 2013.

6. Kluwer, M. W. (2017). Medical microbiology. Indian Journal of Medical Microbiology, 35(1).

7. Chander, J. (2009). Text book of Medical Mycology, Chapter 2, 5, 6, 45, 3 rd edition, Meheta publishers, 9-20,35-36, 266-290.

8. Clinical Laboratory Standards Institute. (CLSI 2009). Method for antifungal disk diffusion susceptibility testing of yeasts, Approved guidelines, 2nd edition, CLSI document, M44 A2, Volume 29, No.17.

9. CLSI. (2012). Reference Method for Broth Dilution Antifungal Susceptibility Testing of Yeasts, Fourth International Supplement, CLSI document M27-4, Wayne, PA, Clinical and Laboratory Standards Institute, 32.

10. Alonso-Valle, H., Acha, O., Garcia-Palomo, J. D., Farinas-Alvarez, C., Fernandez-Mazarrasa, C., \& Farinas, M. C. (2003). Candidemia in a tertiary care hospital: epidemiology and factors influencing mortality. European Journal of Clinical Microbiology and Infectious Diseases, 22(4), 254257.
11. Hube, B. (2004). From commensal to pathogen: stage-and tissue-specific gene expression of Candida albicans. Current opinion in microbiology, 7(4), 336-341.

12. Almeida, A. A. D., Mesquita, C. S. S., Svidzinski, T. I. E., \& Oliveira, K. M. P. D. (2013). Antifungal susceptibility and distribution of Candida spp. isolates from the University Hospital in the municipality of Dourados, State of Mato Grosso do Sul, Brazil. Revista da Sociedade Brasileira de Medicina Tropical, 46(3), 335-339.

13. Furlaneto, M. C., Rota, J. F., Quesada, R. M. B., Furlaneto-Maia, L., Rodrigues, R., Oda, S., ... \& França, E. J. G. D. (2011). Species distribution and in vitro fluconazole susceptibility of clinical Candida isolates in a Brazilian tertiary-care hospital over a 3-year period. Revista da Sociedade Brasileira de Medicina Tropical, 44(5), 595-599.

14. Shanoo, S. (2017). Isolation, Speciation and Characterization of Candida Species in Clinical Isolates, Int. J. Curr. Microbiol. App. Sci, 6(7), 404-413.

15. Pfaller, M. (1996). Nosocomial candidiasis: emerging species, reservoirs, and modes of transmission. Clin Infect Dis. 22 (2), S89-94.

16. Jayalakshmi L, RatnaKumari G, Samson S., (2014), Isolation, Speciation and Antifungal Susceptibility Testing of Candida from Clinical Specimens at a Tertiary Care Hospital, Sch. J. App. Med. Sci, 2(6E), 3193-3198.

17. Chakrabarti, A., Mohan, B., Shrivastava, S.K. (2002). Change in distribution and antifungal susceptibility of Candida species isolated from candidaemia cases in a tertiary care centre during 1996-2000, Indian J Med Res, 116, 5-12.

18. Mokaddas, E. M., Al-Sweih, N. A., \& Khan, Z. U. (2007). Species distribution and antifungal susceptibility of Candida bloodstream isolates in Kuwait: a 10-year study. Journal of Medical Microbiology, 56(2), 255-259.

19. Adhikary, R., \& Joshi, S. (2011). Species distribution and anti-fungal susceptibility of Candidaemia at a multi super-specialty center in Southern India. Indian journal of medical microbiology, 29(3), 309.

20. Basu, S., Gugnani, H. C., Joshi, S., \& Gupta, N. (2003). Distribution of Candida species in different clinical sources in Delhi, India, and proteinase and phospholipase activity of Candida albicans isolates. REVISTA IBEROAMERICANA DE MICOLOGIA., 20(4), 137-140.

21. Yang, Y. L., Cheng, H. H., Lo, H. J., \& TSARY HOSPITALS. (2006). Distribution and antifungal susceptibility of Candida species isolated from different age populations in Taiwan. Medical mycology, 44(3), 237-242.

22. Scoppettuolo, G., Donato, C., De Carolis, E., Vella, A., Vaccaro, L., La Greca, A., \& Fantoni, M. (2014). Candida utilis catheter-related bloodstream infection. Medical mycology case reports, 6, 70-72. 
23. Minari, A., Hachem, R., \& Raad, I. (2001). Candida lusitaniae: a cause of breakthrough fungemia in cancer patients. Clinical infectious diseases, 32(2), 186-190.

24. Capoor, M. R., Nair, D., Deb, M., Verma, P. K., Srivastava, L., \& Aggarwal, P. (2005). Emergence of non-albicans Candida species and antifungal resistance in a tertiary care hospital. Japanese journal of infectious diseases, 58(6), 344.

25. Pradhan, S., Singh, S., Samal, M. P., Murthy, R., \& Pandey, S. (2015). Characterization and antifungal susceptibility pattern of candida spp. isolated from clinical specimens. Journal of evolution of medical and dental sciences-jemds, 4(40), 7004-7012.

26. Samra, Z., Yardeni, M., Peled, N., \& Bishara, J. (2005). Species distribution and antifungal susceptibility of Candida bloodstream isolates in a tertiary medical center in Israel. European Journal of Clinical Microbiology and Infectious Diseases, 24(9), 592-595.

27. Pfaller, M. A., Diekema, D. J., Rinaldi, M. G., Barnes, R., Hu, B., Veselov, A. V., ... \& Gibbs, D. L. (2005). Results from the ARTEMIS DISK Global Antifungal Surveillance Study: a 6.5-year analysis of susceptibilities of Candida and other yeast species to fluconazole and voriconazole by standardized disk diffusion testing. Journal of clinical microbiology, 43(12), 5848-5859.

28. Orasch, C., Marchetti, O., Garbino, J., Schrenzel, J., Zimmerli, S., Mühlethaler, K., ... \& Calandra, T. (2014). Candida species distribution and antifungal susceptibility testing according to European Committee on Antimicrobial Susceptibility Testing and new vs. old Clinical and Laboratory Standards Institute clinical breakpoints: a 6-year prospective candidaemia survey from the fungal infection network of Switzerland. Clinical microbiology and infection, 20(7), 698-705.

29. Roy, R. C., Sharma, G. D., \& Barman, S. R. (2013). Trend of Candida infection and antifungal resistance in a tertiary care hospital of north east India. African Journal of Microbiology Research, 7(24), 3112-3116.

30. Halder, P., Ray, R., Sarker, M., \& kumar Mukherjee, P. Emergence of Non albicans Candida as potential pathogen---Change in spectrum poses therapeutic challenge. BLOOD, 29, 31-5. 